\title{
Cmambu
}

\section{СВЯЗЬ ТРЕТЬЕГО БЛОКА МОЗГА С СОЦИАЛЬНОЙ АКТИВНОСТЬЮ В ПЕРИОД ИНВОЛЮЦИИ}

\author{
О.Л. ЛУШНИКОВА
}

${ }^{a}$ ГБНИУ РХ «Хакасский научно-исследовательский институт языка, литературь и истории», 655017, Россия, Абакан, ул. Шетинкина, д. 23

\section{Резюме}

Цель исследования связана с выявлением связи функций третьего блока мозга (по А.Р. Лурии, программирование, контроль, регуляция деятельности и серийная организация) с уровнем социальной активности. Была выдвинута гипотеза: чем выше уровень социальной активности, тем функции третьего блока мозга более сохранны. В исследовании приняли участие 60 человек (55-65 лет). На первом этапе с испытуемыми проводился опрос, направленный на оценку уровня социальной активности. Было выделено три уровня: низкий, средний и высокий. На втором этапе осуществлялась оценка состояния функций третьего блока мозга методами нейропсихологической диагностики, разработанными А.Р. Лурией и модифицированными Т.В. Ахутиной. С разными пробами, оценивающими состояние функций программирования, контроля и регуляции деятельности, успешно справились испытуемые разных групп. Группа с высоким уровнем социальной активности успешнее справилась с пробой на реакцию выбора; группа среднего уровня - с пробой на исключение лишнего понятия; группа низкого уровня - с пробой на пересказ текста. Практически по всем пробам, связанным с оценкой функций серийной организации, высокие показатели были выявлены в группе высокого уровня активности. Выдвинутая гипотеза подтвердилась частично. Не все функции третьего блока более сохранны в группе высокого уровня. Данные нашего исследования доказали наличие связи между состоянием третьего блока мозга и уровнем социальной активности пожилых людей. Можно предположить, что социальная активность обусловливает сохранность функций программирования, контроля и регуляции деятельности. Возможно, сохранность функций серийной организации определяет возможности социальной активности. Сделан вывод о том, что связь между состоянием третьего блока мозга и социальной активностью у пожилых людей носит двусторонний характер. Полученные результаты могут быть использованы при разработке нейрокогнитивных тренингов для пожилых людей.

Ключевые слова: инволюция, третий блок мозга, социальная активность, функции программирования, контроля и регуляции деятельности, серийная организация. 
Согласно данным Всемирной организации здравоохранения, к середине XXI в. доля людей старше 60 лет будет превышать треть от общей численности населения (World Report..., 2015, p. 44). Такой прогноз повышает интерес к изучению процессов инволюции. Заметные изменения психической деятельности характерны для интервала от 50 до 64 лет (Рощина, Балашова, 2013, c. 151), когда происходит не только изменение привычного образа жизни (Розин, 2017), но и снижение психических функций. На повседневную жизнь пожилых людей влияет дефицит планирования, организации или принятия решений, так как нарушение этих функций ставит под угрозу способность человека вести социально продуктивную жизнь (Lezak, 1982, p. 281). Анатомические структуры, отвечающие за эти функции, локализованы в передних отделах больших полушарий (лобные доли), в зарубежной литературе эти функции обозначаются как «ехеcutive functions», по А.Р. Лурии - это функции программирования, контроля и регуляции деятельности (Лурия, 2008). Согласно его концепции, эти функции входят в третий блок, объединяющий префронтальные и премоторные отделы головного мозга. Префронтальные отделы связаны с функциями программирования, контроля и регулящии деятельности, премоторные - с функцией серийной организацией движений и речи.

Данные исследований нормального старения доказывают, что в период инволюции состояние функций произвольных форм регуляции деятельности меняется. Изменение этих функций, вероятно, связано с ухудшением состояния лобных долей (Lima-Silva et al., 2012, р. 36). При нормальном старении возникают трудности регуляции деятельности (Amieva et al., 2003, p. 129), заметно снижается уровень контроля: пожилым людям сложнее сосредотачивать внимание на выполнении какой-либо задачи (Zanto et al., 2010; Collette et al., 2009). В условиях многозадачности затрудняется переключение, особенно в ситуации неопределенности (Kray et al., 2002, p. 377), из-за снижения скорости обработки информации ухудшается рабочая память (Zimprich, Kurtz, 2012, p. 195).

Естественно, в период инволюции снижается общая двигательная активность, ухудшается серийная организация, что связано со снижением работы премоторных отделов головного мозга. Доказано, что значительное ослабление функций серийной организации происходит уже после 40 лет (Фотекова, Кичеева, 2012, с. 38), с возрастом ухудшается зрительно-моторная координация (Bidi et al., 2014), способность к освоению новых двигательных навыков (Seidler, 2007, p. 17), скорость и точность двигательных навыков (Kornatz et al., 2005, р. 2072). Вместе с тем наряду с возрастными симптомами ограничений в адаптивных возможностях имеются компенсаторные позитивные феномены регуляции психической активности в изменившихся условиях жизнедеятельности (Корсакова, Рощина, 2009, с. 4). Кроме того, доказано, что заметное влияние на сохранение всех психических функций оказывает социальная включенность пожилых людей в социально-политическую и культурную жизнь общества (Zhu et al., 2012). Ряд исследований доказывает, что у активных людей когнитивные функции дольше остаются сохранными (Christensen et al., 1996; Łojko et al., 2015; Fratiglioni et al., 2004; Зборовский, 
Зборовский, 2013). Исследования подтверждают наличие связи между уровнем образования, количеством лет, потраченных на обучение, и общим когнитивным состоянием пожилых людей (Fleck, 2015; Godbole et al., 2016; Łojko et al., 2015). Доказано положительное влияние социальной поддержки семьи и друзей на состояние когнитивных функций в период инволюции (Bassuk et al., 1999; Berkman, 2000; Yeh, Liu, 2003; Yen et al., 2004; Zhu et al., 2012). Одинокие пожилые люди демонстрируют более высокий уровень когнитивных нарушений (Yen et al., 2004), однако степень сохранности психических функций варьируется в зависимости от уровня социальной активности.

Учитывая, что именно состояние функций произвольной регуляции деятельности дает прогноз о смертности у пожилых людей (Johnson et al., 2007), мы поставили цель - выяснить, есть ли связь между состоянием этих функций и социальной активностью у людей пожилого возраста.

В современных условиях информационно-коммуникационные технологии значительно увеличивают возможности социальной интеграции пожилых людей, например, через общение в социальных сетях. Исследования доказывают, что такой вид общения способствует социальной интеграции (Teixeira et al., 2012), однако его связь с когнитивным состоянием пожилых людей еще недостаточно изучена. Включение данного аспекта в понятие социальной активности придает новизну данному исследованию.

Была выдвинута гипотеза: чем выше уровень социальной активности пожилых людей, тем более сохранны у них функции произвольных форм регуляции деятельности.

\section{Методика}

\section{Испытуемые}

Было обследовано 60 человек в возрасте 55-65 лет (равное количество мужчин и женщин, равное количество работающих и неработающих). Все испытуемые с высшим профессиональным образованием, профессиональная деятельность которых (на момент опроса или в прошлом) была связана со сферой образования.

Все испытуемые участвовали в исследовании на добровольной основе. Те испытуемые, которые на момент обследования еще продолжали трудовую деятельность, были рекрутированы из образовательных учреждений, неработающие пожилые люди были рекрутированы из профсоюза работников образования. Средний возраст испытуемых составил 59.53 года (стандартное отклонение - 3.73). Исследование было одобрено этическим комитетом.

\section{Процедура}

Процедура обследования включала два этапа.

На первом этапе с испытуемыми проводился опрос, направленный на оценку уровня социальной активности: подсчитывались баллы, полученные 
при обработке ответов испытуемых на соответствующие вопросы. Принцип расчета баллов представлен в таблице 1.

На втором этапе с испытуемыми проводилось нейропсихологическое обследование.

Функции программирования, контроля и регуляции деятельности оценивались с помощью следующих проб. Проба на реакцию выбора выясняет способность подчинять свои действия речевой инструкции, регулировать их, оттормаживая непосредственные реакции, противоречащие инструкции. Оценке подлежат как способность усвоения инструкции, правильность и темп выполнения, так и наличие уподобления. Проба на исследование свободных u направленных ассоциащий оценивает способность к активному извлечению слов, способность к переключению с одного слова на другое, различению и отбору слов нужной грамматической категории. Важна как продуктивность свободных ассоциаций и глаголов, так и количество повторов, неадекватных слов и ответов фразой. Проба на пересказ текста оценивает способность смысловой адекватности и возможности программирования высказывания. Проба

Таблица 1

Принцип начисления баллов по показателям социальной активности

\begin{tabular}{|c|c|c|}
\hline Показатели & Индикаторы & Баллы \\
\hline \multirow{2}{*}{ Семейное положение } & Замужние/женатые & 2 \\
\hline & Одинокие (разведенные/овдовевшие) & 1 \\
\hline \multirow{2}{*}{ Трудовая занятость } & Работающие & 1 \\
\hline & Неработающие & 0 \\
\hline \multirow{2}{*}{$\begin{array}{l}\text { Предпочитаемый вид } \\
\text { досуга }\end{array}$} & Общение с друзьями & 1 \\
\hline & Общение в социальных сетях & 1 \\
\hline \multirow{4}{*}{ Субъекты общения } & Члены семьи & 1 \\
\hline & Коллеги & 1 \\
\hline & Друзья и знакомые & 2 \\
\hline & Товарищи по интересам & 2 \\
\hline \multirow{4}{*}{$\begin{array}{l}\text { Предпочитаемый способ } \\
\text { общения }\end{array}$} & Вживую & 2 \\
\hline & По телефону & 2 \\
\hline & По скайпу & 1 \\
\hline & В социальных сетях & 1 \\
\hline Уровень общения & Субъективная оценка испытуемым & от 1 до 10 \\
\hline \multirow{2}{*}{ Хобби } & Наличие & 1 \\
\hline & Отсутствие & 0 \\
\hline \multirow{2}{*}{$\begin{array}{l}\text { Общественная/поли- } \\
\text { тическая деятельность }\end{array}$} & Наличие (членство) & 1 \\
\hline & Отсутствие & 0 \\
\hline
\end{tabular}


на исключение лишнего понятия оценивает сохранность вербально-логических операций классификации и обобщения. Необходимо учитывать как количество правильно исключенных, так и количество правильных объяснений. Проба на выполнение ритмов по инструкции показывает способность подчинять свои действия речевой инструкции, в этой пробе оценивается количество правильно выполненных проб с первой попытки.

Функции серийной организации движений и речи оценивались с помощью следующих проб. Проба на динамический праксис оценивает серийную организацию движений, способность к усвоению и автоматизации двигательных программ и переключению от одного движения к другому. Учитывается наличие внешнего опосредования (речевое или местом). Проба на графомоторную координацию оценивает возможность графомоторной и зрительно-моторной координации, способность построения графической двигательной программы, ее автоматизации, переключения от одного элемента к другому, а также скорость выполнения одного графического элемента в секундах и общее время. Проба на рещипрокную координацию позволяет судить о сохранности функций серийной организации движения и межполушарного взаимодействия, оценке подлежит также темп выполнения пробы. Для оценки серийной организации на речевом уровне используется проба на пересказ текста, позволяющая оценить способность к грамматическому оформлению.

Принцип количественной оценки нейропсихологических проб:

- за самостоятельное и безошибочное выполнение ставился максимальный балл (4-6 баллов в зависимости от конкретной пробы);

- за совершение ошибок (в зависимости от грубости ошибок) оценка за выполнение пробы снижалась;

- при условии неспособности выполнить пробу ставился минимальный балл (0 баллов).

Обследование одного человека проводилось индивидуально в течение 4550 минут.

\section{Материаль}

Шкала количественной оценки состояния высших психических функций основана на концепции о трех функциональных блоках мозга А.Р. Лурии (2008). Исследование состояния функций третьего блока мозга производилось с помощью методов нейропсихологической диагностики, разработанных А.Р. Лурией и модифицированных Т.В. Ахутиной (Ахутина и др., 2008).

Для оценки общего состояния функций третьего блока мозга использовались нейропсихологические индексы, которые представляют собой относительные суммарные показатели, объединяющие преимущественно однофакторные параметры выполнения различных проб (Фотекова, 2014). Индексы высчитывались с помощью показателей продуктивности (правильность выполнения) и штрафных баллов (ошибки) по пробам, оценивающим соответствующие функции третьего блока мозга. Были проанализированы три индекса: обобщенный индекс третьего блока мозга, индекс программирования, 
контроля и регуляции деятельности и индекс серийной организации движений и речи.

Статистическая обработка данных осуществлялась с использованием однофакторного дисперсионного анализа ANOVA в прикладном пакете программ IBM SPSS Statistics 19. Был проведен количественный анализ результатов отдельных проб и индексов функций третьего блока мозга.

\section{Результаты}

Результаты опроса, направленного на оценку уровня социальной активности, позволили распределить испытуемых в три группы с разным уровнем. Для распределения анализировались среднее значение (15.72) и стандартное отклонение (3.81). Было выделено три уровня:

1) низкий (10-13 баллов) - 20 человек;

2) средний (14-17 баллов) - 20 человек;

3) высокий (18-26 балла) - 20 человек.

Социально-демографические характеристики испытуемых представлены на рисунке 1.

В группе людей с высожим уровнем больше женщин; тех, кто состоит в браке; и тех, кто продолжает трудовую деятельность. В группе со средним уровнем активности примерно одинаковое количество испытуемых по всем показателям. В группе с низким уровнем примерно одинаковое количество одиноких людей и состоящих в браке, но почти в два раза больше мужчин и тех, кто прекратил свою трудовую деятельность.

Результаты однофакторного дисперсионного анализа (ANOVA) показали, что состояние разных функций третьего блока мозга в группах с разным уровнем различается. Статистически значимые различия между группами были обнаружены в трех пробах, связанных с оценкой функций программирования, контроля и регуляции деятельности: проба на реакцию выбора, проба на исключение лишнего понятия и проба на пересказ текста (таблица 2).

С пробой на реакцию выбора лучше других справились испытуемые группы с высоким уровнем социальной активности, различия с группой низкого уровня статистически значимы $(p=0.018)$. Хотя испытуемые группы высокого

Рисунок 1

Социально-демографические характеристики испытуемых (чел.)

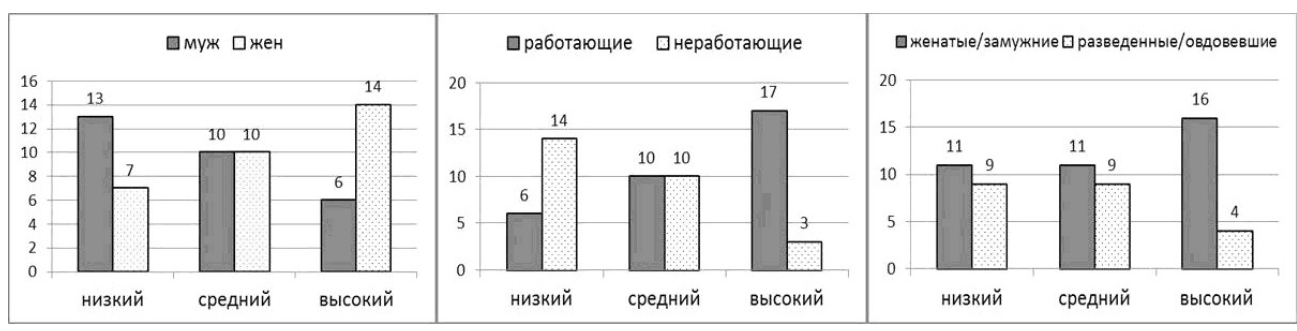


Таблица 2

Результаты выполнения проб на оценку состояния функций программирования, контроля и регуляции деятельности в группах с разным уровнем социальной активности

\begin{tabular}{|c|c|c|c|c|c|c|c|}
\hline \multirow{2}{*}{ Показатель } & \multirow{2}{*}{$\begin{array}{c}\text { Низкий } \\
\text { (1) }\end{array}$} & \multirow{2}{*}{$\begin{array}{c}\text { Средний } \\
\text { (2) }\end{array}$} & \multirow{2}{*}{$\begin{array}{c}\text { Высокий } \\
\text { (3) }\end{array}$} & \multicolumn{2}{|c|}{ ANOVA } & \multirow{2}{*}{$1-2$} & \multirow{2}{*}{$1-3$} \\
\hline & & & & $\mathbf{F}$ & $p$ & & \\
\hline \multicolumn{8}{|c|}{ Проба на реакцию выбора } \\
\hline $\begin{array}{l}\text { Правильность } \\
\text { выполнения }\end{array}$ & 2.65 & 2.95 & 3.35 & 3.695 & $0.031^{*}$ & & $0.018^{*}$ \\
\hline $\begin{array}{l}\text { Наличие } \\
\text { уподобления }\end{array}$ & 0.75 & 0.65 & 0.35 & 1.988 & 0.146 & & $0.093 \sim$ \\
\hline \multicolumn{8}{|c|}{ Проба на исключение лишнего понятия } \\
\hline $\begin{array}{l}\text { Количество } \\
\text { правильно } \\
\text { исключенных слов с } \\
\text { первой попытки }\end{array}$ & 3.30 & 4.10 & 3.85 & 3.777 & $0.029 *$ & $0.028^{*}$ & \\
\hline $\begin{array}{l}\text { Количество } \\
\text { правильных } \\
\text { объяснений }\end{array}$ & 3.30 & 4.10 & 3.85 & 3.933 & $0.025^{*}$ & $0.023^{*}$ & \\
\hline \multicolumn{8}{|c|}{ Проба на пересказ текста } \\
\hline $\begin{array}{l}\text { Смысловая } \\
\text { адекватность }\end{array}$ & 2.65 & 2.20 & 1.95 & 4.998 & $0.010^{*}$ & $0.043^{*}$ & $0.019 *$ \\
\hline $\begin{array}{l}\text { Возможность } \\
\text { построения } \\
\text { высказывания }\end{array}$ & 2.60 & 2.35 & 2.15 & 3.237 & $0.047^{*}$ & & $0.063 \sim$ \\
\hline
\end{tabular}

$\sim p<0.05,{ }^{*} p<0.05$.

уровня совершали меньше ошибок уподобления, различия по этому показателю не достигли уровня значимости $(p=0.093)$.

В пробе на исключение лишнего понятия высокие результаты показали испытуемые группы со средним уровнем социальной активности. Они чаще других давали правильный ответ с первой попытки $(p=0.028)$ и давали этому правильное объяснение $(p=0.023)$. Статистически значимые различия были обнаружены между этой группой и группой низкого уровня.

Более успешное выполнение пробы на пересказ текста продемонстрировала группа с низким уровнем социальной активности. Статистически значимые различия с группой среднего уровня были обнаружены по показателю правильности понимания смысла предъявленного текста $(p=0.043)$. Хотя испытуемые низкого уровня социальной активности реже пропускали смысловые звенья при построении рассказа, различия с группой высокого уровня присутствуют лишь на уровне тенденции $(p=0.063)$.

Пробы, направленные на оценку состояния функций серийной организации движений, показали более высокие результаты у группы с высоким уровнем 
социальной активности (таблица 3). Статистически значимые различия были выявлены преимущественно между группами низкого и высокого уровней.

В пробе на динамический праксис испытуемые группы с высоким уровнем социальной активности чаще демонстрировали плавное выполнение или переход к нему от замедленного при выполнении первой $(p=0.001)$ и второй $(p=0.000)$ двигательных программ, а также быстрое переключение с одного движения на другое $(p=0.002$ и $p=0.001)$.

Выполнение двигательной программы в пробе на реципрокную координацию $(p=0.01)$ и построение графической программы в пробе на графомоторную координацию $(p=0.003)$ также лучше в группе с высоким уровнем социальной активности.

Обобщенный индекс серийной организации движения выше в группе с высоким уровнем социальной активности (рисунок 2), причем различия с группой низкого уровня статистически значимы $(p=0.019)$.

Вместе с тем показатели серийной организации на речевом уровне (в пробе на пересказ текста) выше в группе с низким уровнем социальной активности, причем различия с группой высокого уровня статистически значимые $(p=0.009)$.

Таблица 3

Результаты выполнения проб на оценку состояния функций серийной организации в группах с разным уровнем социальной активности

\begin{tabular}{|c|c|c|c|c|c|c|c|}
\hline \multirow{2}{*}{ Показатель } & \multirow{2}{*}{$\begin{array}{l}\text { Низкий } \\
\text { (1) }\end{array}$} & \multirow{2}{*}{$\begin{array}{l}\text { Средний } \\
\text { (2) }\end{array}$} & \multirow{2}{*}{$\begin{array}{c}\text { Высокий } \\
\text { (3) }\end{array}$} & \multicolumn{2}{|c|}{ ANOVA } & \multirow{2}{*}{$1-2$} & \multirow{2}{*}{$1-3$} \\
\hline & & & & $\mathbf{F}$ & $p$ & & \\
\hline \multicolumn{8}{|c|}{ Проба на динамический праксис } \\
\hline $\begin{array}{l}\text { Автоматизированность } \\
\text { 1-й программы }\end{array}$ & 2.60 & 3.05 & 3.30 & 7.992 & $0.001 * *$ & $0.068 \sim$ & $0.002 * *$ \\
\hline $\begin{array}{l}\text { Серийная организация } \\
\text { 1-й программы }\end{array}$ & 2.60 & 2.80 & 3.20 & 6.186 & $0.004^{* *}$ & & $0.001^{* *}$ \\
\hline $\begin{array}{l}\text { Автоматизированность } \\
\text { 2-й программы }\end{array}$ & 2.70 & 3.05 & 3.35 & 6.816 & $0.002 * *$ & & $0.001^{* *}$ \\
\hline $\begin{array}{l}\text { Серийная организация } \\
\text { 2-й программы }\end{array}$ & 2.40 & 2.75 & 3.10 & 6.862 & $0.002 * *$ & & $0.000^{* *}$ \\
\hline \multicolumn{8}{|c|}{ Проба на графомоторную координацию } \\
\hline Серийная организация & 3.00 & 3.65 & 4.15 & 6.007 & $0.004^{* *}$ & & $0.003^{* *}$ \\
\hline \multicolumn{8}{|c|}{ Проба на реципрокную координацию } \\
\hline Серийная организация & 2.80 & 3.20 & 3.45 & 4.481 & $0.016^{*}$ & & $0.01 *$ \\
\hline \multicolumn{8}{|c|}{ Проба на пересказ текста } \\
\hline Грамматический строй & 2.80 & 2.65 & 2.30 & 5.380 & $0.007^{* *}$ & & $0.009^{* *}$ \\
\hline
\end{tabular}

$\sim p<0.05,{ }^{*} p<0.05 .,{ }^{* *} p<0.01$. 
Для выяснения связи социальной активности с состоянием функций третьего блока мозга был произведен анализ корреляций между индексами этого блока мозга и показателями активности из таблицы 1. Статистически значимые корреляции были обнаружены с трудовой занятостью испытуемых и уровнем общения (таблица 4).

У тех испытуемых, которые еще продолжают трудовую деятельность, показатели функций третьего блока мозга (в том числе серийной организации) выше. Кроме того, чем выше уровень общения испытуемых, тем показатели функций третьего блока мозга в целом и функции серийной организации у испытуемых выше.

\section{Обсуждение результатов}

В данном исследовании проверялась гипотеза о том, что состояние функций третьего блока мозга связано с уровнем социальной активности. Предполагалось: чем выше уровень, тем функции третьего блока мозга более

Рисунок 2

Среднегрупповые показатели индекса серийной организации в группах с разным уровнем социальной активности

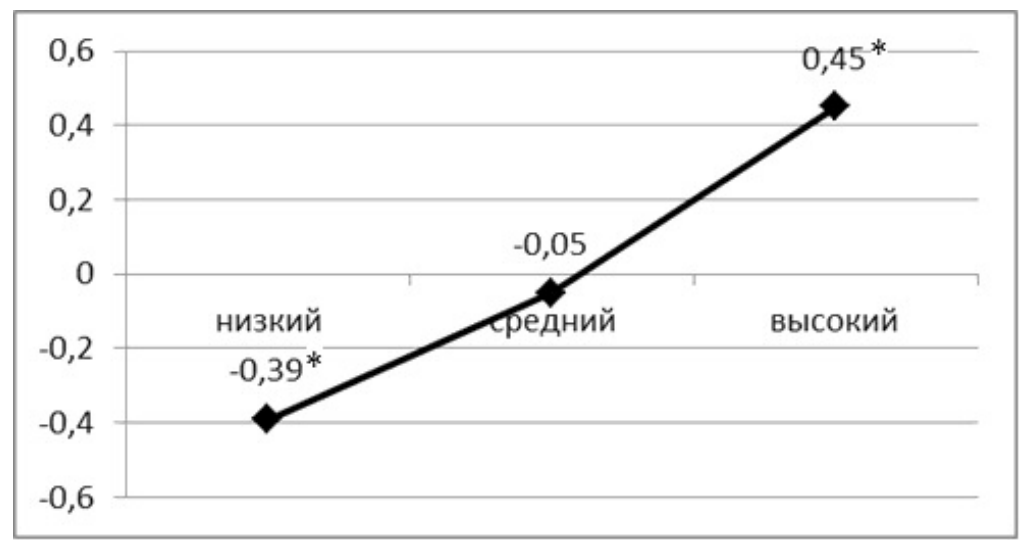

Таблица 4

Корреляции индексов с показателями социальной активности

\begin{tabular}{|l|l|c|c|}
\hline \multicolumn{1}{|c|}{ Показатели } & \multicolumn{1}{|c|}{$\begin{array}{c}\text { Индекс третьего } \\
\text { блока мозга }\end{array}$} & $\begin{array}{c}\text { Индекс серийной } \\
\text { организации }\end{array}$ \\
\hline \multirow{2}{*}{ Трудовая занятость } & $r$ (Пирсон) & 0.307 & 0.340 \\
\cline { 2 - 4 } & $p$ & 0.017 & 0.008 \\
\hline \multirow{2}{*}{$\begin{array}{l}\text { Уровень общения } \\
\text { (субъективная оценка) }\end{array}$} & $r(П и р с о н)$ & 0.338 & 0.356 \\
\cline { 2 - 4 } & $p$ & 0.008 & 0.005 \\
\hline
\end{tabular}


сохранны. Гипотеза подтвердилась частично: не все функции этого блока более сохранны в группе высокого уровня социальной активности.

Результаты исследования показали, что с разными пробами, оценивающими состояние функций программирования, контроля и регуляции деятельности, успешно справились испытуемые разных групп. Можно выдвинуть несколько предположений. Во-первых, возможно, эти функции у испытуемых изначально развивались неравномерно (т.е. и в более молодом возрасте), а с началом инволюционных процессов эта неравномерность сохранилась или даже усугубилась. Во-вторых, есть вероятность, что именно неравномерность этих функций обусловила разные возможности социальной активности. Ведь доказано, что именно высокий уровень когнитивных функций является предпосылкой для определенных видов деятельности, т.е. состояние психических функций может оказывать влияние на деятельность и тем самым отражать когнитивную компетентность (Salthouse et al., 1990; Hultsch et al., 1999).

Возможно, именно состояние функций программирования определило возможности социальной активности испытуемых: группа с высоким уровнем лучше других выполнила пробу на реакцию выбора. Эта проба связана с точностью принимаемых решений, способностью подчинять свои действия инструкции и оттормаживать действия, противоречащие инструкции. Можно сказать, что в этой группе достаточно хорошо сохранны функции контроля и регуляции деятельности, которые помогают пожилым людям вырабатывать новые модели поведения с учетом возрастных изменений и тем самым способствовать ведению социально активного образа жизни.

Вместе с тем данные разных исследований доказывают, что участие пожилых людей в общественной деятельности и наличие активного насыщенного досуга положительно коррелируют с сохранностью когнитивных функций (Yen et al., 2004; Christensen et al., 1996; Fratiglioni et al., 2004), поэтому нельзя исключать вероятность того, что именно социальная активность способствовала сохранности этих функций. В данном случае целесообразно говорить о двусторонней связи функций программирования и социальной активности: не только сохранность функций программирования обусловливает возможности пожилых людей для активной социальной жизни, но и социальная активность определяет состояние когнитивных функций.

Данные некоторых исследований доказывают, что уровень активности играет незначительную роль в сохранении когнитивных функций, и когнитивная производительность, несмотря на разные факторы, все равно будет ухудшаться с возрастом (Christensen et al., 1996, p. 79). Например, испытуемые со средним уровнем социальной активности успешнее других справились с пробой на исключение лишнего понятия. Можно считать, что в этой группе более сохранна способность к логическим операциям, так как проба построена таким образом, что нужно классифицировать понятия, выбирать неподходящее и аргументировать свой выбор. Однако ограниченность полученных данных не позволяет однозначно утверждать, что́ определило сохранность логического мышления в этой группе. Не все научные работы подтверждают влияние социальной активности на сохранение когнитивных функций. Например, 
лонгитюдные исследования доказывают, что сохранению когнитивных функций способствует не конкретная деятельность, а общий социально-экономический статус (Aartsen et al., 2002).

Испытуемые низкого уровня успешнее всех справились с пробой на пересказ текста (оценкой речевого программирования). Сложно представить, что именно низкий уровень социальной активности способствовал сохранению когнитивных функций. Сохранность речевого программирования в этой группе, вероятнее всего, объясняется характером трудовой деятельности испытуемых. Профессиональная деятельность испытуемых всех уровней (на момент обследования или в прошлом) была связана с интеллектуальной работой и вербальным общением (в сфере образования), что, вполне возможно, обусловило сохранность функций программирования на речевом уровне. Доказано, что именно интеллектуальная активность (а не столько социальная) смягчает когнитивный спад в старости (Hultsch et al., 1999).

Кроме того, результаты опроса на определение уровня социальной активности показали, что в этой группе испытуемые больше предпочитают интеллектуальные виды деятельности (чтение газет, журналов, книг), нежели социальные (общение с друзьями, общение в социальных сетях) (таблица 5).

Хотя данные некоторых исследований доказывают, что речевое программирование вообще более устойчиво к влиянию возраста, поэтому эти функции у пожилых людей дольше остаются сохранными, однако снижение функций серийной организации, по мнению исследователей, уже заметно после 40 лет (Фотекова, Кичеева, 2012, с. 38).

Результаты нашего исследования показали, что функции серийной организации движений более сохранны у высокосоциализированных испытуемых (статистически значимые различия были обнаружены практически по всем пробам, оценивающим состояние этих функций).

По мнению исследователей, именно премоторная кора лежит в основе поведенческой гибкости, которая необходима при выполнении сложных двигательных актов, требующих одновременно зрительного восприятия, концентрации внимания, способности игнорировать помехи и собственно выполнения движений (Wise et al., 1996). Естественно полагать, что именно гибкость поведения

Таблииа 5

Распределение испытуемых по предпочитаемым видам досуга в группах с разным уровнем социальной активности

\begin{tabular}{|l|c|c|c|c|}
\hline \multirow{2}{*}{$\begin{array}{c}\text { Уровень } \\
\text { социальной }\end{array}$} & \multicolumn{4}{|c|}{ Виды досуга } \\
\cline { 2 - 5 } активности & \multicolumn{2}{|c|}{ Социальные } & \multicolumn{2}{|c|}{ Интеллектуальные } \\
\cline { 2 - 5 } & $\begin{array}{c}\text { Общение с } \\
\text { друями }\end{array}$ & $\begin{array}{c}\text { Общение } \\
\text { в соц. сетях }\end{array}$ & Чтение книг & $\begin{array}{c}\text { Чтение газет, } \\
\text { журналов }\end{array}$ \\
\hline Низкий & 5 & 0 & 7 & 8 \\
\hline Средний & 10 & 3 & 9 & 5 \\
\hline Высокий & 12 & 7 & 10 & 3 \\
\hline
\end{tabular}


позволяет пожилым людям вести активный социальный образ жизни: привыкать к новым условиям жизни после прекращения трудовой деятельности, находить новые сферы интересов и самореализации, включаться в общественную жизнедеятельность и т.д. Поэтому можно предположить, что именно сохранность функций серийной организации (премоторных отделов) определяет социальную активность пожилых людей.

Несмотря на это, данные исследований доказывают положительную роль общественной деятельности в жизни пожилых людей. Например, исследование К.Э. Зборовского в доме-интернате для пенсионеров и инвалидов показало, что вовлечение людей в социально значимую деятельность привело к положительным изменениям, связанным не столько с восстановлением функциональной способности опорно-двигательного аппарата, сколько с раскрытием потенциала личности. Основным механизмом, определившим данные изменения, был перенос акцентов с невозможности передвижения на необходимость конструктивной деятельности, что проявляет потенциал личности, скрытый за пассивным ожиданием помощи и поддержки (Зборовский, Зборовский, 2013). Сложно сказать, что именно социальная активность определяет поддержание двигательных функций (в том числе и серийной организации), возможно, сохранность этих функций зависит и от других факторов (например, личностной мотивации пожилых людей).

Таким образом, данные нашего исследования доказали наличие связи между состоянием функций третьего блока мозга и уровнем социальной активности пожилых людей. Во-первых, социальная активность обусловливает сохранность функций программирования, контроля и регуляции деятельности. Во-вторых, сохранность функций серийной организации определяет возможности социальной активности. Связь между социальной активностью и состоянием третьего блока мозга у пожилых людей носит двусторонний характер.

Состояние функций третьего блока мозга, согласно полученным результатам, положительно коррелирует с продолжением трудовой деятельности испытуемых, а также с уровнем их общения. Хотя не было выявлено положительной связи между состоянием функций третьего блока мозга пожилых людей и их общением в социальных сетях, тем не менее этот вид общения расширяет их возможности (особенно если их передвижение ограничено) и повышает общий уровень социальной активности.

В целом нельзя отрицать положительную роль социальной активности пожилых людей. Данные различных исследований доказывают, что низкая активность (социальная и интеллектуальная) связана с более низким уровнем когнитивных функций у пожилых людей (Christensen et al., 1996), а активный и социально интегрированный образ жизни в пожилом возрасте защищает от деменции (Fratiglioni et al., 2004). 


\title{
Литература
}

Ахутина, Т. В., Полонская, Н. Н., Пылаева, Н. М., Максименко, М. Ю. (2008). Нейропсихологическое обследование. В кн. Т. В. Ахутина, О. Б. Иншакова (ред.), Нейропсихологическая диагностика, обследование письма и чтения младших школьников (с. 4-64). М.: Сфера/В. Секачев.

Зборовский, К. Э., Зборовский, Д. К. (2013). Социальная реабилитация пожилого человека. Охрана труда и сощиальная защита, 2, 90-95.

Корсакова, Н. К., Рощина, И. Ф. (2009). Нейропсихологический подход к исследованию нормального и патологического старения. Неврология, нейропсихиатрия, психосоматика, 1(3-4), 4-8.

Лурия, А. Р. (2008). Высшие корковые функции человека. СПб.: Питер.

Розин, В. М. (2017). Старость как психологический и культурный феномен. Психология. Журнал Высшей школы экономики, 14(2), 320-337.

Рощина, И. Ф., Балашова, Е. Ю. (2013). Клиническая психология старения в России: истоки, проблемы и перспективы. В кн. Н. В. Зверева, И. Ф. Рощина, С. Н. Ениколопов (ред.), Медицинская (клиническая) психология: традиции и перспективы (с. 142-156). М.: МГППУ/НЦПЗ РАМН. Режим доступа: http://www.medpsy.ru/library/library154.pdf

Фотекова, Т. А. (сост.). (2014). Практикум по нейропсихологической диагностике: учебно-методический комплекс по дисциплине (2-е изд., испр. и доп.). Абакан: ХГУ им. Н.Ф. Катанова.

Фотекова, Т. А., Кичеева, А. О. (2012). Состояние высших психических функций в ранней, средней и поздней взрослости: нейропсихологический анализ. Культурно-историческая психология, 8(2), 36-44.

Ссылки на зарубежные источники см. в разделе References после англоязычного блока.

Лушникова Ольга Леонидовна - старший научный сотрудник, сектор экономики и социологии, ГБНИУ РХ «Хакасский научно-исследовательский институт языка, литературы и истории», кандидат социологических наук.

Сфера научных интересов: нейропсихология нормального старения.

Контакты: oltolt@mail.ru

\section{Connection of the Third Brain Block with Social Activity in Involution}

\section{O.L. Lushnikova ${ }^{a}$}

${ }^{a}$ The Khakass Scientific Research Institute of Language, Literature and History, 23 Shchetinkina Str., Abakan, Republic of Khakassia, Russian Federation

\begin{abstract}
The objective of the study is to reveal the connection of the third brain block (according to A.R. Luria - functions of programming, control and serial organization) with social activity. The hypothesis is following: the higher is the level of social activity, the better preserved are the functions of the third brain block. The general sample consisted of 60 participants (from 55 to 65 years old). In the first stage of the study the participants were interviewed for assessment of their
\end{abstract}


level of social activity (low, middle and high). The second stage was neuropsychological diagnostics (elaborated by A.R. Luria and modified by T.V. Akhutina). The different groups successfully carried out different tasks on functions of programming, control and regulation of activity. The high-level group was better in the test on reaction of choice; the average-level group - in the test on the exclusion of irrelevant concept; the low-level group - in the task of the retelling. However, the high level group successfully carried out tasks on serial organization. The hypothesis was partially confirmed. Not the whole third block is more preserved in the high-level group. The connection between the third brain block and social activity is proved. Two main conclusions: probably, the social activity determines the preservation of the functions of programming, control and regulation; perhaps, the preservation of the serial organization determines the capabilities of social activity. We conclude that the connection between social activity and the third brain block is bilateral. The obtained results can be used in the elaboration of neurocognitive training for the elderly.

Keywords: involution, the third brain block, social activity, executive function, motor function.

\section{References}

Aartsen, M. J., Smits, C. H., Tilburg, T., Knipscheer, K. C., \& Deeg, D. J. (2002). Activity in older adults: cause or consequence of cognitive functioning? A longitudinal study on everyday activities and cognitive performance in older adults. Journal of Gerontology. Series B, Psychological Sciences and Social Sciences, 57, 153-162.

Akhutina, T. V., Polonskaya, N. N., Pylaeva, N. M., \& Maksimenko, M. Yu. (2008). Neyropsikhologicheskoe obsledovanie [Neuropsychological assessment]. In T. V. Akhutina \& O. B. Inshakova (Eds.), Neyropsikhologicheskaya diagnostika, obsledovaniye pis'ma i chteniya mladshikh shkolnikov [Neuropsychological diagnostics, assessment of writing and reading in younger schoolchildren] (pp. 4-64). Moscow: Sfera/V. Sekachev. (in Russian)

Amieva, H., Phillips, L., \& Della Salaa, S. (2003). Behavioral dysexecutive symptoms in normal aging. Brain and Cognition, 53(2), 129-132. doi:10.1016/S0278-2626(03)00094-0

Bassuk, S. S., Glass, T. A., \& Berkman, L. F. (1999). Social disengagement and incident cognitive decline in community - dwelling elderly persons. Annals of Internal Medicine, 131, 165-173. doi:10.4236/ojepi.2013.32006

Berkman, L. F. (2000). Which influences cognitive function: Living alone or being alone? Lancet, 355, 1291-1292. doi:10.1016/S0140-6736(00)02107-3

Bidi, Z., Akbarfahimi, M., Jafarzadepur, E., \& Hasanimehraban, A. (2014). A comparative study of visual perception in the elderly residing in Sabzevar. Quarterly Journal of Sabzevar University of Medical Sciences, 20(4), 416-422.

Christensen, H., Korten, A., Jorm, A. F., Henderson, A. S., Scott, R., \& Mackinnon, A. J. (1996). Activity levels and cognitive functioning in an elderly community sample. Age Ageing, 25, 72-80. doi:10.1093/ageing/25.1.72

Collette, F., Schmidt, C., Scherrer, C., Adam, S., \& Salmon, E. (2009). Specificity of inhibitory deficits in normal aging and Alzheimer's disease. Neurobiology of Aging, 30, 875-889. doi:10.1016/j.neurobiolaging.2007.09.007 
Fleck, Ch. (2015). Cognitive functions as possible predictors of performance on instrumental activities of daily living and perceived cognitive health in elderly individuals. Lubbock, TX: Texas Tech University Health Sciences Center.

Fotekova, T. A. (Ed.). (2014). Praktikum po nejropsihologicheskoj diagnostike: uchebno-metodicheskij kompleks po discipline [Practicum on neuropsychological diagnostics: educational-methodical complex on the discipline]. Abakan: Khakass State University. (in Russian)

Fotekova, T. A., \& Kicheyeva, A. O. (2012). Higher mental functions in early, middle and late adulthood: a neuropsychological analysis. Kul'turno-istoricheskaya Psikhologiya [Cultural-Historical Psychology], 8(2), 36-44. (in Russian)

Fratiglioni, L., Paillard-Borg, S., \& Winbland, B. (2004). An active and socially integrated lifestyle in late might protect against dementia. Lancet Neurology, 3(6), 343-353.

Godbole, Sh., Godbole, G., \& Vaidya, S. (2016). Influence of education on cognitive function in the elderly population of Pune city. International Journal of Research in Medical Sciences, 4(9), 4119-4122. doi:10.18203/2320-6012.ijrms20162945

Hultsch, D. F., Hertzog, C., Small, B. J., \& Dixon, R. A. (1999). Use it or lose it: engaged lifestyle as a buffer of cognitive decline in aging? Psychology and Aging, 14, 245-263. doi:10.1037/08827974.14.2.245

Johnson, J. K., Lui, L.-Y., \& Yaffe, K. (2007). Executive function, more than global cognition, predicts functional decline and mortality in elderly women. The Journals of Gerontology: Series A, 62(10), 1134-1141. doi:10.1093/gerona/62.10.1134

Kornatz, K. W., Christou, E. A., \& Enoka, R. M. (2005). Practice reduces motor unit discharge variability in a hand muscle and improves manual dexterity in old adults. Journal of Applied Physiology, 98(6), 2072-2080.

Korsakova, N. K., \& Roshchina, I. F. (2009). Neuropsychological approach to studying normal and abnormal aging. Neurology, Neuropsychiatry, Psychosomatics, 1(3-4), 4-8. (in Russian)

Kray, J., Li, K. Z. H., \& Lindenberger, U. (2002). Age-related changes in task-switching components: The role of task uncertainty. Brain and Cognition, 49, 363-381. doi:10.1006/brcg.2001.1505

Lezak, M. D. (1982). The problem of assessing executive functions. International Journal of Psychology, 17(1-4), 281-297. doi:10.1080/00207598208247445

Lima-Silva, T. B., Fabriciom, A. T., Vinholi e Silva, L. S., Oliveira, G. M., Turci da Silva, W., Kissaki, P. T., ... Yassuda, M. S. (2012). Training of executive functions in healthy elderly: Results of a pilot study. Dementia and Neuropsychologia, 6(1), 35-41. doi:10.1590/S1980-57642012DN06010006

Łojko, D., Wegner, A., \& Czajkowska, A. (2015). Factors contributing to cognitive deficits in elderly residents of rural areas. European Review for Medical and Pharmacological Sciences, 19, 2590-2596.

Luria, A. R. (2008). Vysshiye korkovye funktsii cheloveka [The higher cortical functions of a human]. Saint Petersburg: Piter. (in Russian)

Roshchina, I. F., \& Balashova E. Yu. (2013). Klinicheskaya psikhologiya stareniya v Rossii: istoki, problemy i perspektivy [Clinical psychology of aging in Russia: origins, problems and prospects]. In N. V. Zvereva, I. F. Roshchina, \& S. N. Enikolopov (Eds.), Meditsinskaya (klinicheskaya) psikhologiya: traditsii $i$ perspektivy [Medical (clinical) psychology: traditions and prospects] (pp. 142-156). Moscow: MSUPE/ Mental Health Research Center. Retrieved from http://www.medpsy.ru/library/library154.pdf (in Russian)

Rozin, V. M. (2017). Old age as a psychological and cultural phenomenon. Psychology. Journal of the Higher School of Economics, 14(2), 320-337. (in Russian) 
Salthouse, T. A., Kausler, D. H., \& Saults, J. S. (1990). Age, self-assessed health status and cognition. Journal of Gerontology, 45, 156-160.

Seidler, R. D. (2007). Aging affects motor learning but not savings at transfer of learning. Learning and Memory, 14(1-2), 17-21.

Teixeira, V., Pires, C., Pinto, F., Freitas, J., Dias, M. S., \& Rodrigues, E. M. (2012). Towards elderly social integration using a multimodal human-computer interface. In Proceedings of the 2nd International Living Usability Lab Workshop on AAL Latest Solutions, Trends and Applications (pp. 3-13). Retrieved from https://pdfs.semanticscholar.org/29c7/bc9c475bb381ddde547aa2a71c5e1890397a.pdf

Wise, S. P., Pellegrino, G., \& Boussaoud, D. (1996). The premotor cortex and nonstandard sensorimotor mapping. Canadian Journal of Physiology and Pharmacology, 74(4), 469-482.

World Report on Ageing and Health by World Health Organization. (2015). Luxembourg: WHO Press.

Yeh, Sh.-Ch. J., \& Liu, Y.-Y. (2003). Influence of social support on cognitive function in the elderly. BMC Health Services Research, 3, 9. doi:10.1186/1472-6963-3-9

Yen, Y. C., Yang, M. J., Shih, Ch. H., \& Lung, F. W. (2004). Cognitive impairment and associated risk factors among aged community members. International Journal of Geriatric Psychiatry, 19, 564-569. doi:10.1002/gps.1131

Zanto, T. P., Hennigan, K., Ostberg, M., Clapp, W. C., \& Gazzaley, A. (2010). Predictive knowledge of stimulus relevance does not influence top-down suppression of irrelevant information in older adults. Cortex, 46, 564-574.

Zborovskii, K. E., \& Zborovskii, D. K. (2013). Sotsialnaya reabilitatsiya pozhilogo cheloveka [Social rehabilitation of the elderly people. Health and social protection]. Okhrana Truda i Sotsialnaya Zashchita, 2, 90-95. (in Russian)

Zhu, Sh., Hu, J., \& Efird, J. T. (2012). Role of social support in cognitive function among elders. Journal of Clinical Nursing, 21, 2118-2125. doi:10.1111/j.1365-2702.2012.04178.x

Zimprich, D., \& Kurtz, T. (2012). Individual differences and predictors of forgetting in old age: the role of processing speed and working memory. Aging Neuropsychology and Cognition, 20(2), 195-219. doi:10.1080/13825585.2012.690364

Olga L. Lushnikova - senior research, The Khakass Scientific Research Institute of Language, Literature and History, Ph.D.

Research area: neuropsychology of normal aging.

E-mail: oltolt@mail.ru 